\title{
Revisión radiocarbónica y cronocultural del Neolítico antiguo de la Balma Margineda (Aixovall, Andorra)
}

\author{
Chronocultural and radiocarbon revision of the Early Neolithic in Balma Margineda \\ (Aixovall, Andorra)
}

\author{
F. Xavier Oms ${ }^{\mathrm{a}}$, Juan F. Gibaja ${ }^{\mathrm{b}}$, Niccolò Mazzucco ${ }^{\mathrm{c}}$ y Jean Guilaine ${ }^{\mathrm{d}}$
}

\section{RESUMEN}

En este trabajo se presentan y evalúan las 10 dataciones disponibles para los niveles neolíticos de la Balma Margineda (Andorra). Después de analizar la naturaleza de las muestras y sus contextos arqueoestratigráficos de procedencia, consideramos que únicamente tres de ellas, realizadas recientemente, son aceptables. Éstas confieren una horquilla mucho más rejuvenecida de la ocupación de la que se proponía en base a las dataciones antiguas. En este nuevo escenario se analiza el material cerámico y lítico de los niveles in situ, para situar adecuadamente el yacimiento en el marco actual del conocimiento del Neolítico antiguo en esta región pirenaica.

\begin{abstract}
This work discusses the radiocarbon evidence from the Neolithic layers of the Balma Margineda (Andorra). Since the last excavation campaigns during the '90s, a total of ten $14 C$ dates has been obtained. We discuss their stratigraphic provenance and suggest that only three of the ten 14C dates should be considered reliable. The new dates assign the Neolithic occupations to a more recent chronology. Moreover, we also present a brief revision of the ceramic and lithic materials from the in situ Neolithic layers, in order reinterpret the site using the most recent data on the Early Neolithic of Pyrenean region.
\end{abstract}

Palabras clave: Neolítico antiguo; 14C; Cerámica cardial e impresa; Estratigrafía; Andorra; Península Ibérica.

Key words: Early Neolithic; 14C; Cardial ware; Stratigraphy; Andorra; Iberia.

\section{INTRODUCCIÓN}

La Balma Margineda es un abrigo de dimensiones medias a unos 970 metros s.n.m., situado en el desfiladero del río Valira, en la localidad andorrana de Aixovall (Fig. 1). Pere Canturri inició las excavaciones en este yacimiento en los años 1950. En ellas colaboró en algunos momentos Joan Maluquer de Motes (1962), quien publicó los primeros resultados. La información arqueoestratigráfica extraída de esas intervenciones es enormemente escasa, por no decir casi inexistente. A partir de 1979, un equipo encabezado por Jean Guilaine y Michel Martzluff retoma los trabajos arqueológicos que finalizaron en 1991. Poco después publicaron la primera monografía del yacimiento en 3 volúmenes con los resultados completos de las actuaciones efectuadas en

\footnotetext{
a Seminari d'Estudis i Recerques Prehistòriques (SERP, 2014SGR-108). Dept. de Prehistòria, Història Antiga i Arqueologia. Universitat de Barcelona. C/Montalegre 6-8. 08001 Barcelona. Correo e.: xavieroms@gmail.com

b Institució Milà i Fontanals, Consejo Superior de Investigaciones Científicas (IMF-CSIC). C/ Egipcíaques 15, 08001 Barcelona. Correo e.: jfgibaja@imf.csic.es

c Fondation Fyssen postdoctoral fellow, UMR 7055, Préhistoire et Technologie, CNRS - Université Paris Ouest Nanterre la Défense. 21 allée de l’Université. 92023 Nanterre cedex. France. Correo e.: nicco.mazzucco@gmail.com

${ }^{d}$ Collège de France. Pl. Marcelin Berthelot 11. 75005 París.

Correo e.: jguilaine@wanadoo.fr

Recibido 17-VI-2015; aceptado 6-IX-2015.
} 


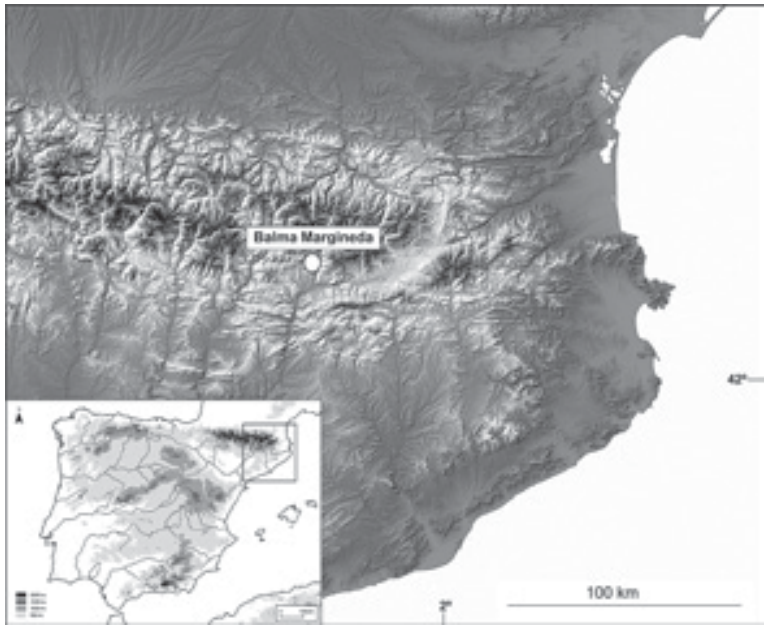

Fig. 1. Localización del yacimiento de la Balma Margineda (Andorra). Base cartográfica del Institut Cartogràfic de Catalunya, modificada por G. Remolins.

los niveles neolíticos y mesolíticos (Guilaine y Martzluff 1995a).

Las dataciones muy antiguas obtenidas y unos materiales que se asociaban mal con el denominado "Paradigma Cardial" se convirtieron en una referencia para el estudio del Neolítico antiguo de la región pirenaica. Eso provocó la inclusión del yacimiento en el grupo del entonces llamado "Neolítico Pericardial" (Guilaine 1993). Este grupo se caracterizaba por unas fechas antiguas, pocas cerámicas con morfología y decoración típicas del Neolítico Cardial y conjuntos faunísticos donde los taxones salvajes eran mayoritarios. Otros ejemplos paradigmáticos de este grupo eran el Abri de Jean Cros (Guilaine et al. 1979) y el Abri de Roc de Dourgne (Guilaine et al. 1993). En los últimos años, los trabajos en distintas áreas del Pirineo proponen que sean simplemente registros culturalmente poco representativos, con problemas y resultados dudosos de las fechas radiocarbónicas debido a las muestras datadas (Manen y Guilaine 2010; Oms et al. 2012; Valdeyron et al. 2013).

Las dataciones disponibles de la Balma Margineda sirvieron además para explicar la rápida llegada de colonos con cerámica cardial a la Cueva de Chaves, proponiendo una vía de entrada neolítica por el Languedoc francés, cruzando la región de la Cerdanya y avanzando por el río Segre hacia el Cinca hasta los territorios oscenses (Baldellou y Utrilla 1999; Petit 2001; Alday et al. 2012). Según trabajos posteriores esta vía de entrada, quizá probable, no se podía sustentar en la información de la Balma Margineda por las diferencias significativas de su registro arqueológico (sobre todo por las características formales y decorativas de la cerámica) y por la calidad de las dataciones realizadas (Oms et al. 2012).

\section{ESTRATIGRAFÍA Y CULTURA MATERIAL (CERÁMICA E INDUSTRIA LÍTICA)}

La Balma Margineda es un yacimiento cuya compleja estratigrafía abarca desde una cronología histórica (estratos superficiales y nivel C1) al final del Paleolítico superior -Aziliense- (Guilaine y Martzluff 1995a; Guilaine et al. 2008). Los niveles del Neolítico antiguo (C3), abordados en este trabajo, tienen múltiples variaciones según tramos. En la secuencia más elemental se suceden las fases C3a (más reciente), C3b y C3b base (más antigua), lo que se observaba bien en el tramo sur del yacimiento, por ejemplo en el perfil entre los cuadros E-F/26-27 (Fig. 2A). La variabilidad lateral era tan amplia, que pocos metros hacia el centro del área excavada, en el perfil I-F/22-23, esta secuencia ya no se documentaba. La afectación de las excavaciones antiguas de Canturri y diversas estructuras negativas alteraron la estratigrafía. Por ello en este tramo se usó la nomenclatura $\mathrm{C}_{3} \mathrm{~F}_{1}, \mathrm{C}_{3} \mathrm{~F}_{2}$ y $\mathrm{C} 3 \mathrm{~F}_{3}$ (Fig. 2B), correspondiente a los estratos que están en contacto con la gran fosa $\mathrm{C} 3 \mathrm{~F}$. La descripción de los niveles y las estructuras más destacables es la siguiente (Guilaine y Martzluff 1995b):

Nivel C2: es prácticamente estéril y cierra la secuencia prehistórica. De naturaleza detrítica, está compuesto por arenas y gravas heterométricas.

Nivel C3a: cronológicamente perteneciente al Neolítico antiguo, se caracteriza por limos grisáceos con un componente arcilloso casi inexistente. En su base se suceden carbones y cenizas que oscurecen este tramo. Estaba alterado por actuaciones no reguladas, por lo que sólo pudo ser excavado adecuadamente en unos pocos tramos. Se han documentado dos estructuras de combustión y dos agujeros de poste. Como el nivel inferior C3b, estaba afectado por la fosa C3f y quizá también la $\mathrm{C} 3 \mathrm{~F}$, aunque dicha determinación era compleja en algunos tramos. 

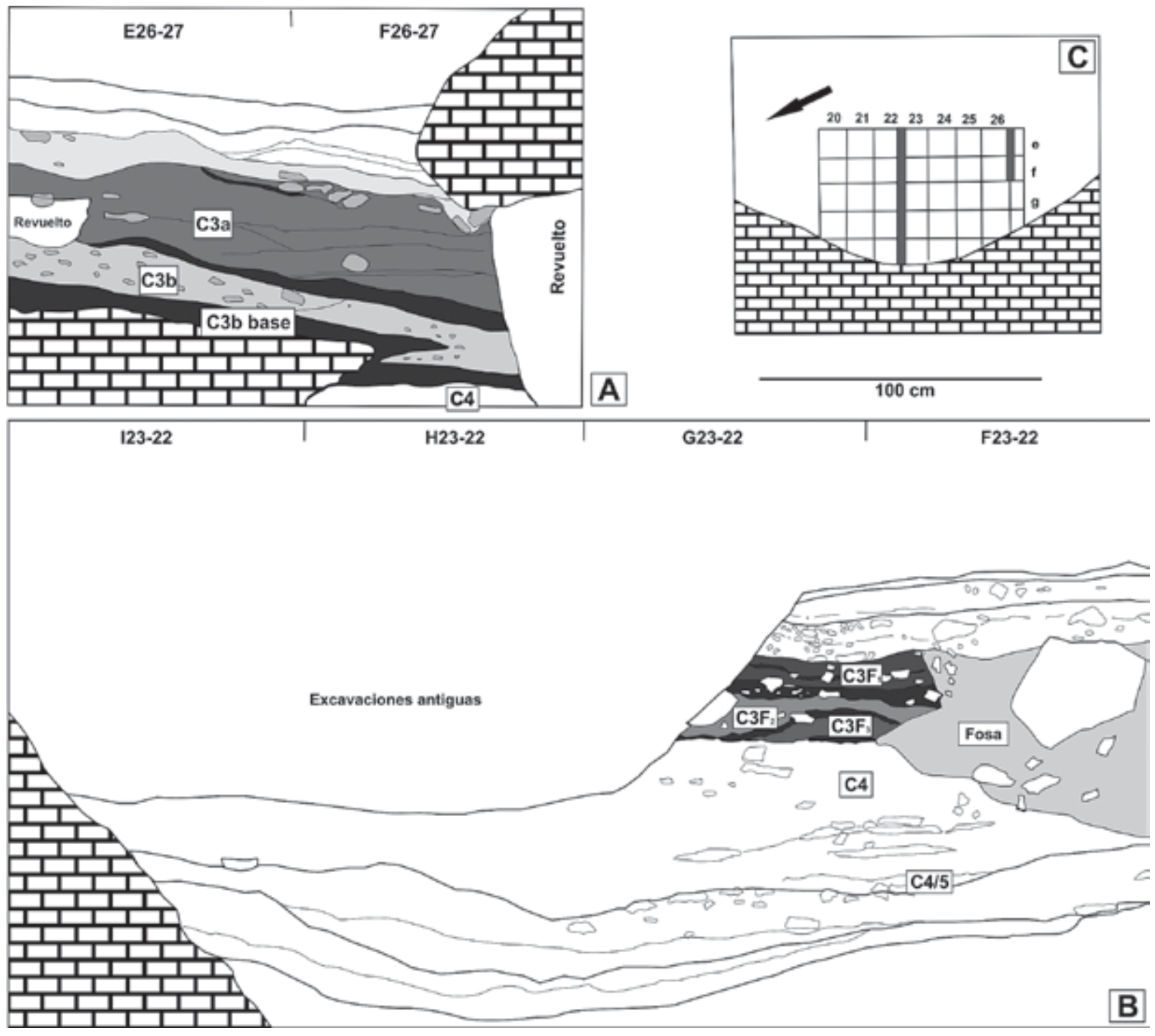

Fig. 2. Balma Margineda: cortes estratigráficos A y B, localizados en la planta del yacimiento (C).

Nivel C3b: presenta una matriz de limos y arenas con gravas heterométricas de coloración marrón. Estaba alterado por las grandes fosas $\mathrm{C} 3 \mathrm{f}$ y C3F. Se distribuía por una zona menor que la del nivel C3a. Ocupaba el tramo oeste, el más protegido por el abrigo, y su ocupación fue intensa. Se reconocieron una estructura de combustión (con avellanas carbonizadas) y una concentración de carbones y cenizas, probablemente un hogar desmantelado o lavado.

Nivel C3b base: apenas contiene restos cerámicos pero fue considerada la capa neolítica más antigua del yacimiento. Presenta bloques decimétricos y gravas incluidas en limos carbonosos de coloración marrón. Se describe como el resultado de una ocupación de poca intensidad. Aparece en toda la superficie del abrigo. Entre un lecho de bloques se hallaron dos estructuras de combustión y una acumulación de plaquetas enrojecidas por la acción del fuego.

Fosa C3f: mide $100 \mathrm{~cm}$ de profundidad y 120 $\mathrm{cm}$ de diámetro máximo. Está constituida por una matriz de limos polvorientos de color marrón. En su tramo superior había otra estructura negativa, 
más pequeña. Se excavó desde el nivel $\mathrm{C} 3 \mathrm{a}$ y llega hasta los niveles mesolíticos.

Fosa C3F: las dimensiones máximas son 145 x 110 x $130 \mathrm{~cm}$. Su relleno es heterogéneo con numerosos bloques y clastos de distribución y tamaños variables. La matriz es limosa y la coloración marrón rosada. En algunos cuadros corta parte de los niveles neolíticos C3b y C3b base y de los mesolíticos subyacentes. Probablemente está cubierto por el nivel C3a. Sin embargo, en otros tramos (Fig. 2B) esta estructura se desarrolla junto a una estratificación no típica, definida como $\mathrm{C}_{3} \mathrm{~F}_{1}, \mathrm{C}_{3} \mathrm{~F}_{2}$ y $\mathrm{C} 3 \mathrm{~F}_{3}$, que son sus estratos de contacto. Su cultura material la sitúa cronológicamente en el Neolítico antiguo.

En estos niveles, el material arqueológico procedente de los estratos in situ es relativamente pobre. Analizaremos brevemente los restos cerámicos y el utillaje lítico, incluidos en dos tesis doctorales ${ }^{1}$ recientemente defendidas. Su análisis se encuadra en una lectura actual del proceso de neolitización y es muy útil para comprender el yacimiento, así como para interpretar el origen de dicho proceso en el noreste de la Península Ibérica.

\subsection{La cerámica}

Es un material relativamente abundante en la Balma Margineda, pero los fragmentos decorados son muy pobres y no siempre proceden de los niveles considerables in situ. Sin embargo, aún siendo muy escasos, son enormemente representativos de este periodo. Los fragmentos corresponden a 53 vasos, de los que 38 tienen una correcta posición estratigráfica: 16 del nivel $\mathrm{C} 3 \mathrm{a}, 4$ del C3b, 7 del C3f y 11 del C3F. Mediante analogía y similitudes el resto puede relacionarse, con ciertas reservas, con los niveles $\mathrm{C} 3 \mathrm{a}, \mathrm{C} 3 \mathrm{~F}$ y $\mathrm{C} 3 \mathrm{f}$. Hemos dispuesto de estos escasos datos para correlacionarlos con las dataciones (Fig. 3 y Tab. 1).

${ }^{1}$ Mazzucco, N. 2014: The Human Occupation of the Southern Central Pyrenees: a traceological approach to flaked stone assemblages. Tesis doctoral inédita. Universitat Autònoma de Barcelona, $432 \mathrm{pp}$.

Oms, F. X. 2014: La neolitització del nord-est de la Península Ibèrica a partir de les datacions de ${ }^{14} \mathrm{C}$ i les primeres ceràmiques impreses c.5600-4900 cal BC. Tesis doctoral inédita. Universitat de Barcelona, $472 \mathrm{pp}$.

\begin{tabular}{|l|c|c|c|c|c|c|}
\hline & C3a & C3f & C3F & C3b & $\begin{array}{c}\text { Sin } \\
\text { contexto }\end{array}$ & Total \\
\hline Cardial & 1 & - & - & 3 & 1 & 5 \\
\hline $\begin{array}{l}\text { Cardial + } \\
\text { impresión }\end{array}$ & - & - & 1 & 1 & 1 & 3 \\
\hline Peine & 1 & - & - & - & - & 1 \\
\hline $\begin{array}{l}\text { Impresión } \\
\text { simple }\end{array}$ & 5 & 1 & 4 & - & 1 & 10 \\
\hline $\begin{array}{l}\text { Impresión + } \\
\text { acanalado }\end{array}$ & 2 & - & - & - & 1 & 3 \\
\hline Cordón liso & 3 & 2 & 1 & - & 1 & 8 \\
\hline Cordón impreso & - & 1 & 3 & - & 6 & 10 \\
\hline Acanalado & 3 & 2 & - & - & 3 & 8 \\
\hline Incisión & 1 & 1 & - & - & 1 & 3 \\
\hline Boquique & - & - & 2 & - & - & 2 \\
\hline $\begin{array}{l}\text { Total vasos } \\
\text { decorados }\end{array}$ & 16 & 7 & 11 & 4 & 15 & 53 \\
\hline
\end{tabular}

Tab. 1. Decoraciones de los vasos de la Balma Margineda. Se presentan los totales sin datos porcentuales por el reducido número de ejemplares.

El nivel $\mathrm{C} 3 \mathrm{~b}$ tiene 17 fragmentos de los que solo 4 corresponden a vasos decorados. Tres pertenecen a otros tantos vasos de pequeño tamaño dadas las claras diferencias en su pasta, morfología y tipología de la impresión decorativa. P. Canturri recuperó el cuarto vaso, más completo, mayoritariamente fuera de contexto. Sin embargo, conocemos su procedencia por haberse hallado un fragmento del mismo in situ en el nivel $\mathrm{C} 3 \mathrm{~b}$ de las excavaciones de Guilaine y Martzluff. Su morfología es esférica con borde de tendencia entrante y labio redondeado. el acabado es pulido y la cocción irregular (Fig. 3.10). La decoración combina las impresiones sucesivas mediante una herramienta simple (punzón, caña de hueso) y las impresiones cardiales mediante concha pequeña o recortada, en posición oblicua. El esquema decorativo consta de una franja horizontal de impresiones simples debajo del labio, limitada por impresiones cardiales. Del cuerpo central descienden franjas verticales con la misma estructuración.

La estructura $\mathrm{C} 3 \mathrm{~F}$ cuenta con 11 vasos decorados (89 fragmentos en total): 1 combina la técnica cardial con impresiones simples (Fig. 3.1), 4 solo muestran esas improntas (Fig. 3.6 y

Trab. Prehist., 73, N. ${ }^{\circ}$ 1, enero-junio 2016, pp. 29-46, ISSN: 0082-5638

doi: $10.3989 /$ tp.2016.12162 


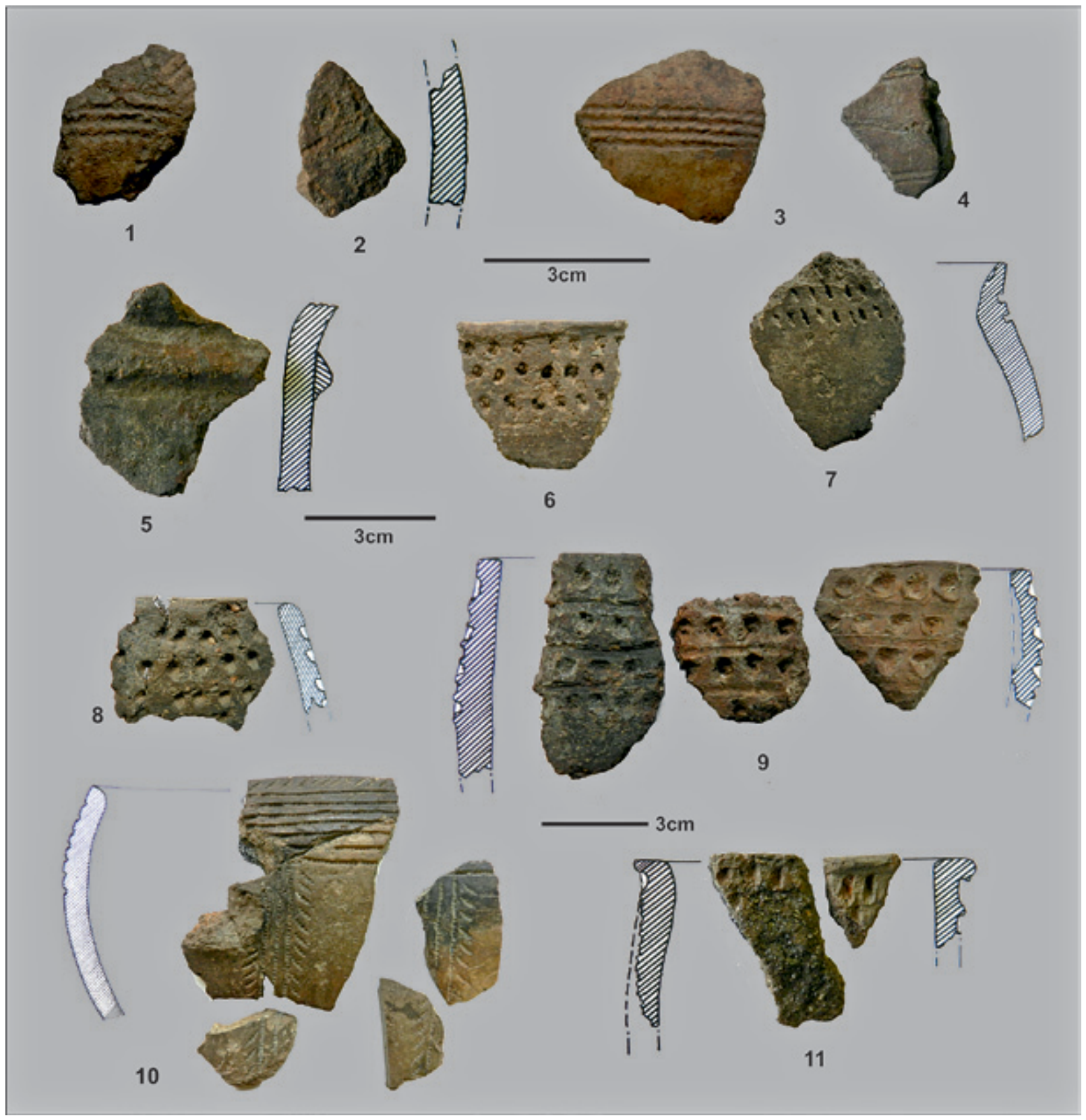

Fig. 3. Cerámicas de la Balma Margineda. Niveles C3a: 4, 8- 9, 11 y C3b: 2-3 (excavaciones antiguas), 10 (excavaciones antiguas excepto el fragmento de la derecha, procedente de C3b); Fosas C3F: 1, 6-7 y C3f: 5.

7), 3 presentan un cordón impreso y 1 tiene un cordón liso. Destacamos dos vasos con decoración boquique.

En la estructura C3f solo hay 7 vasos (65 fragmentos): un par de acanalados, un par de cordones lisos (Fig. 3.5), cordones impresos, incisiones y la combinación de cardial e impresión simple en un único recipiente.

Por último, en los 16 vasos (71 fragmentos) del nivel C3a la impresión simple se aprecia en 5 efectivos. Los vasos con acanalados e incisiones suman 4 elementos y los cordones lisos 3. Otros 
dos combinan impresión simple y acanalado (Fig. 3.9). Las técnicas cardial y peine se emplean sólo en un vaso.

\subsection{La industria lítica tallada}

Jean Guilaine y Michel Martzluff recuperaron 1.153 restos líticos tallados en los niveles neolíticos de sus excavaciones. Sólo 106 piezas están retocadas (Tab. 2). Una gran parte de este conjunto son fragmentos de rocas metamórficas, cuarzo y cristal de roca. El utillaje en sílex tiene una escasa representatividad. Guilaine y Martzluff (1995c) describen en detalle estas diferentes litologías en el capítulo correspondiente. A nivel tecnológico, las rocas se explotaron para la obtención de lascas pequeñas. Sólo los escasos productos laminares, muchos fragmentados, están confeccionados en sílex. La escasez de núcleos y de productos de mantenimiento en esta roca sugiere que solo un parte de la producción se llevó a cabo in situ. Probablemente la población de Balma Margineda llevó al asentamiento los núcleos ya preformados.

El análisis funcional se ha centrado en un conjunto de 90 piezas. Incluye la práctica totalidad de lascas y láminas en sílex y una pequeña muestra de productos sobre otras litologías, principalmente cuarzo y cuarcita. Su objetivo fue adquirir nue-

\begin{tabular}{|l|c|c|c|c|c|}
\hline Capa 3 & $\begin{array}{c}\text { Restos } \\
\text { de talla }\end{array}$ & $\begin{array}{c}\text { \% } \\
\text { restos } \\
\text { de talla }\end{array}$ & $\begin{array}{c}\text { Reto- } \\
\text { cados }\end{array}$ & $\begin{array}{c}\text { Arma- } \\
\text { duras }\end{array}$ & $\begin{array}{c}\text { \% } \\
\text { retocados }\end{array}$ \\
\hline $\begin{array}{l}\text { 2/3 y 3 } \\
\text { sup }\end{array}$ & 22 & 13,6 & 3 & 0 & 0,0 \\
\hline 3F & 27 & 18,5 & 5 & 1 & 20,0 \\
\hline 3f & 848 & 4,8 & 41 & 6 & 14,6 \\
\hline 3a & 69 & 18,8 & 13 & 3 & 23,1 \\
\hline 3b & 92 & 19,6 & 18 & 4 & 22,2 \\
\hline 3b base & 26 & 42,3 & 11 & 2 & 18,2 \\
\hline 3/4 & 69 & 21,7 & 15 & 2 & 13,3 \\
\hline Total & $\mathbf{1 1 5 3}$ & 9,2 & $\mathbf{1 0 6}$ & $\mathbf{1 8}$ & 17,0 \\
\hline
\end{tabular}

Tab. 2. Restos líticos tallados de la Balma Margineda presentes en las capas 3 y de transición (2/3 y 3/4) (según Guilaine y Martzluff 1995a). vos datos sobre las actividades paleoeconómicas realizadas mediante el utillaje lítico tallado. Los resultados no han sido óptimos por las intensas alteraciones post-deposicionales sufridas por el material en superficie. No hemos podido analizar todas las piezas seleccionadas, ni siempre fue posible diagnosticar con precisión las huellas de uso observadas. Así del conjunto analizado hemos podido detectar rastros de utilización en 25 piezas (correspondiente a 26 zonas usadas, pues una presenta dos filos usados).

Los microlitos geométricos son los instrumentos sobre los que hemos podido obtener más información. La mayoría son triángulos: el 44\% (n. 11) del conjunto de materiales con huellas de uso. Las fracturas de impacto nos confirma que se emplearon como elementos de proyectil. El resto de útiles se destinaron al tratamiento de la piel, probablemente en estado seco (n. 5; 20\%) y al raspado de alguna materia vegetal, sea plantas no leñosas o madera (n. $2 ; 8 \%$ ). Finalmente, el estado de conservación de 7 piezas $(28 \%)$ y el escaso desarrollo de los rastros en las mismas nos han impedido determinar con exactitud sobre qué materia actuaron pero sí aproximarnos a su dureza (materia blanda, semidura o dura).

\section{PROBLEMAS ESTRATIGRÁFICOS VERSUS DATACIONES RADIOCARBÓNICAS}

La calidad de las dataciones se ha convertido en los últimos años en uno de los aspectos más relevantes en las interpretaciones arqueológicas. En nuestro caso, y siguiendo a Bernabéu (2006) y Zilhão (2011), hemos evaluado la muestra datada, la seguridad del contexto arqueológico y la relación con el material documentado. Más allá de las problemáticas propias de las dataciones radiocarbónicas y de las seriaciones establecidas a partir de la cerámica, la Balma Margineda tiene un problema común a todas las estratigrafías complejas en cueva o abrigo. Los niveles holocenos del yacimiento tienen una matriz muy suelta y polvorienta, además de numerosos hogares y estructuras negativas (fosas de diferente tamaño y agujeros de poste), así como madrigueras y cicatrices erosivas de diferente magnitud. Esto provocó, sin duda, una transmisión de materiales,

Trab. Prehist., 73, N. ${ }^{\circ}$ 1, enero-junio 2016, pp. 29-46, ISSN: 0082-5638

doi: $10.3989 /$ tp.2016.12162 
tanto vertical (entre niveles) como horizontal (en un mismo nivel), como demuestra la presencia de semillas domésticas y cerámica en los niveles adscritos al Mesolítico (Marinval 1995). Este hecho es habitual en numerosos yacimientos y secuencias arqueológicas de este periodo (Brochier 1995; Guilaine y Martzluff 1995a; Bernabéu et al. 2001; Antolín 2008).

Muchas variables antrópicas (durante la ocupación), post-deposicionales y tafonómicas provocan que aquello que denominamos por convención "nivel", sea a menudo un palimpsesto resultado de numerosas ocupaciones. Éstas pueden ser muy cercanas en el tiempo (Beeching y Brochier 2003), como se ha observado en la Cova Colomera (Oms et al. 2013) o la Cova del Toll (Guilaine et al. 1981; Martín 1993). En la Balma Margineda, tales variables antrópicas y tafonómicas se tradujeron en una estratigrafía muy compleja, con numerosos lentejones laterales y tramos con un desarrollo estratigráfico muy diferenciado (Guilaine y Martzluff 1995b).

\section{LAS DATACIONES DE LA BALMA MARGINEDA}

Este yacimiento, desde la publicación de sus niveles neolíticos en el año 1995, se convirtió en un punto clave para explicar las ocupaciones de alta montaña por las primeras comunidades agricultoras y pastoras. Lo arcaico de las dataciones obtenidas y los discursos teóricos que se plantearon, centrados en explicar un tránsito local entre las comunidades mesolíticas y neolíticas (Pallarés et al. 1997; Bosch et al. 1998), favorecieron su conversión en referencia obligada en la época. Incluso han seguido usándose en propuestas recientes (Isern et al. 2012; Alday et al. 2012).

Las 10 dataciones radiocarbónicas disponibles proceden de la primera monografía del yacimiento (Guilaine y Martzluff 1995a), de un artículo que analiza nuevas problemáticas sobre los materiales datados (Martins et al. 2015) y del proyecto $\mathrm{I}+\mathrm{D}$ : “Aproximación a las primeras comunidades neolíticas del NE peninsular a través de sus prácticas funerarias (HAR2011-23149)" en cuyo marco se han realizado expresamente para este trabajo.

\subsection{La primera serie de dataciones}

Las dataciones holocenas de la Balma Margineda publicadas en la monografía (Guilaine et al. 1995b) caracterizaban las capas más fiables a nivel arqueológico (C3a y C3b), el tránsito hacia el Mesolítico (C3b base y C3/4) y las capas propiamente mesolíticas (C4, C5 y C6). El resultado de la correlación de estas dataciones era mayoritariamente coherente (Tab. 3). Al emplearse el sistema radiométrico convencional para cada datación fueron necesarios entre 10 y $30 \mathrm{~g}$ de carbón. La cantidad se intentó reunir con carbones de un solo cuadro (Guilaine et al. 1995b: 93).

Sin embargo las estructuras negativas identificadas desde su apertura removieron y mezclaron diferentes horizontes, lo que no aseguraba la procedencia exacta del material datado. Este hecho, en una estratigrafía tan compleja como la Balma Margineda, debió suponer la inclusión fortuita de carbones de varias procedencias, quizás de niveles distintos, para lograr la cantidad requerida para la datación. Las tres fechas de los niveles neolíticos proceden de muestras recogidas del interior de las

\begin{tabular}{|l|l|c|c|c|c|c|c|}
\hline \multicolumn{1}{|c|}{ Nivel } & Muestra & Método & Lab $\#$ & $\delta^{13} \mathbf{C}$ & BP & Var. & Cal BC 2 $\sigma$ \\
\hline C3a-F1 & Carbones & Convencional & Ly-3288 & - & 6640 & 160 & $5885-5305$ \\
\hline C3b-F3 & Carbones & Convencional & Ly-3289 & - & 6850 & 150 & $6016-5510$ \\
\hline C3b base F3 base & Carbones & Convencional & Ly-2839 & - & 6670 & 120 & $5806-5375$ \\
\hline C3/4 & Carbones & Convencional & Ly-3290 & - & 6820 & 170 & $6047-5473$ \\
\hline
\end{tabular}

Tab. 3. Primera serie de dataciones radiocarbónicas neolíticas de la Balma Margineda (Guilaine et al. 1995a), calibradas mediante el programa OxCal v.4.2. con la curva IntCal13 (Reimer et al. 2013). 
estructuras de combustión C3-F1 y C3-F3. Estos potentes hogares se intercalaban en los niveles $\mathrm{C} 3 \mathrm{a}, \mathrm{C} 3 \mathrm{~b}$ y $\mathrm{C} 3 \mathrm{~b}$ base, aunque con una relación estratigráfica poco clara, ya que también están en contacto con la gran fosa C3F. Ello unido a la antigüedad de las fechas y a su amplia variación estándar podría indicar que, efectivamente, se incorporaron por azar carbones procedentes de los estratos mesolíticos. Por estas razones, proponemos considerar dudosas y, por tanto, no representativas, tales dataciones radiocarbónicas, algo que ya se ha hecho (Morales et al. 2010). Cabe puntualizar que las estructuras de combustión de donde proceden estas primeras fechas no han vuelto a ser datadas.

\subsection{Segunda serie de dataciones}

En el curso del desarrollo de una tesis doctoral enmarcada en el proyecto The Neolithic in the Mediterranean Basin (SFRH/BD/44089), se tomaron muestras de yacimientos ibéricos y norteafricanos, entre los cuales se encontraba la Balma Margineda (Martins et al. 2015). Fueron seleccionadas tres muestras arqueobotánicas (Tab. 4): una Leguminosae, procedente del contacto entre los niveles 4 y 5 (Mesolítico) y dos fragmentos de avellana (Corylus avellana) de los niveles $\mathrm{C} 3 \mathrm{~b}$ y C3a, ambos del Neolítico antiguo.

La datación mesolítica es muy parecida a las disponibles para estos niveles en la primera serie por lo que no haremos mayores comentarios. En cambio, las dataciones del Neolítico antiguo muestran un claro rejuvenecimiento respecto a las anteriores. El problema es que reflejan una inversión estratigráfica: el nivel más reciente, el C3a, posee la fecha más antigua. Además, ambas presentan episodios estadísticamente distintos, lo que en efecto implica una inversión real.
La monografía no menciona que los restos de avellana pertenezcan a alguna estructura del nivel C3a, pero sí su dispersión en el mismo (22 restos en total). En cambio, en el C3b, este taxón se localiza en la estructura de combustión 4-F2 (Guilaine et al. 1995a: 123). La avellana es una muestra de vida corta, que forma parte de los recursos recolectados habitualmente consumidos en el Mesolítico y cuyo consumo desciende durante el Neolítico (Marinval 1995: 69). El análisis antracológico también documenta Corylus avellana tanto en los niveles mesolíticos como neolíticos (Heinz y Vernet 1995: 40).

Más allá del problema de la inversión estratigráfica, desde el punto de vista cultural destacamos la total incompatibilidad entre el tipo de cerámica y la datación de C3a. Esta es demasiado antigua y sólo relacionable con otros conjuntos precardiales de tipo Impressa-ligur, ausentes en la Balma Margineda. De ahí la impresión de que el nivel C3a pudiera haber sufrido problemas de contaminación de sedimentos de distintos niveles a raíz de la excavación de la estructura C3f.

En conclusión, rechazamos la datación de $\mathrm{C} 3 \mathrm{a}$ por su antigüedad y por el problema de la inversión estratigráfica. En cambio, consideramos válida la de $\mathrm{C} 3 \mathrm{~b}$, más reciente y obtenida sobre una muestra segura: una concentración de avellanas en una estructura de combustión.

\subsection{Tercera serie de dataciones}

En el marco del citado proyecto HAR201123149, fechamos un conjunto de muestras de fauna. Su selección no fue sencilla porque la escasa cuantía de los restos y su fragmentación nos impidió en muchos casos determinar no sólo el tipo de hueso, sino especialmente la especie a la que correspondía. Se intentó, en la medida de lo

\begin{tabular}{|c|c|c|c|c|c|c|c|}
\hline Nivel & Muestra & Método & Lab \# & $\delta^{\mathbf{1 3}} \mathbf{C}$ & BP & Var. & Cal BC 2 $\sigma$ \\
\hline C3b & Corylus avellana (fruto) & AMS & Beta-325682 & -22.8 & 6410 & 40 & $5472-5322$ \\
\hline C3a & Corylus avellana (fruto) & AMS & Beta-325681 & -24.7 & 6630 & 40 & $5626-5491$ \\
\hline
\end{tabular}

Tab. 4. Segunda serie de dataciones radiocarbónicas de la Balma Margineda (Martins et al. 2015), calibradas mediante el programa OxCal v.4.2. con la curva IntCal13 (Reimer et al. 2013).

Trab. Prehist., 73, N. ${ }^{\circ}$ 1, enero-junio 2016, pp. 29-46, ISSN: 0082-5638

doi: $10.3989 /$ tp.2016.12162 


\begin{tabular}{|c|c|c|c|c|c|c|c|}
\hline Nivel & Muestra & Método & Lab \# & $\delta^{\mathbf{1 3}} \mathbf{C}$ & BP & Var. & Cal BC 2 $\sigma$ \\
\hline C3-F1 (hogar) & Ovis/Capra & AMS & CNA-2680.1.1. & -17.36 & 5472 & 54 & $4451-4233$ \\
\hline C3F (fosa) & Ovis/Capra & AMS & CNA-2681.1.1 & -31.3 & 6083 & 38 & $5207-4849$ \\
\hline C3a (nivel) & Ovis/Capra & AMS & CNA-2679.1.1 & -17.15 & 5850 & 35 & $4797-4612$ \\
\hline C3f (fosa) & Capra pyrenaica & AMS & CNA-2682.1.1. & -24.91 & 7401 & 37 & $6390-6216$ \\
\hline
\end{tabular}

Tab. 5. Tercera serie de dataciones radiocarbónicas de la Balma Margineda, calibradas mediante el programa OxCal v.4.2. con la curva IntCal13 (Reimer et al. 2013).

posible, la elección de taxones domésticos, siendo los dientes la mejor de las opciones. Las cinco muestras escogidas fueron datadas mediante AMS en el Centro Nacional de Aceleradores (Sevilla). Una de ellas debió desecharse por deficiencias en la calidad y cantidad del colágeno pero los resultados de las restantes fueron positivos (Tab. 5).

La datación CNA-2680.1.1 (5472 \pm 54 BP,

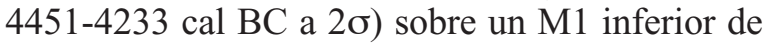
Ovis/Capra procede de la estructura de combustión C3-F1, correlativa y contemporáneo al nivel $\mathrm{C} 3 \mathrm{a}$. El resultado, muy reciente, no se puede hacer corresponder con el nivel C3a. Podría tratarse de una polución posterior dado que se encuentra en contacto con el nivel $\mathrm{C} 2$, por lo que la datación CNA-2680.1.1 debe ser rechazada, aunque probablemente se relacione con la última frecuentación neolítica del abrigo.

La datación CNA-2681.1.1 (6083 \pm 38 BP, 5207-4849 cal BC a 2б) fue realizada sobre un P3 superior de Ovis/Capra. Fecha parte de la amortización de la gran estructura C3F (145 x 110 x $130 \mathrm{~cm}$ ), situada entre los cuadros F23 a D23. En este tramo no se identificó la típica secuencia de C3a-C3b-C3b base (Guilaine et al. 1995a: 117). Cubría esta estructura un nivel neolítico con registro material poco caracterizado. Los autores propusieron que esta fosa fue excavada en el nivel $\mathrm{C} 3 \mathrm{a}$, pero con limitaciones, ya que, como se ha dicho, no se encontró en este tramo del yacimiento. Posteriormente fue cubierta por un lentejón lateral poco representativo del nivel $\mathrm{C} 3 \mathrm{a}$. El valor de $\delta 13 \mathrm{C}$ es extraordinariamente elevado para este tipo de muestra, lo que podría indicar algún tipo de contaminación. A pesar de ello, consideramos el resultado de la datación aceptable de manera preliminar, gracias a los factores de orden estrati- gráfico y su relación con los resultados obtenidos en otros yacimientos (Oms et al. 2013; Polo et al. 2014).

La datación CNA-2679.1.1 (5850 \pm 35 BP, 4797-4612 cal BC a $2 \sigma$ ) se hizo sobre un radio de Ovis/Capra procedente del cuadro F22 del nivel $\mathrm{C} 3 \mathrm{a}$. En este tramo del abrigo sí que se constata la estratigrafía clásica antes citada. Consideramos que esta datación es plenamente representativa, tanto por la muestra utilizada y su contexto, como por la relación con el material recuperado. La fecha rejuvenece de manera notable las otras dataciones obtenidas de este mismo nivel, que se situaban alrededor del 5626-5491 cal BC (Martins et al. 2015) y 5885-5305 cal BC (Guilaine et al. 1995b).

Por último, la datación CNA-2682.1.1 se ejecutó sobre un M1/M2 inferior, probablemente de Capra pirenaica, de la fosa C3f (de $120 \mathrm{~cm}$ de diámetro máximo por $100 \mathrm{~cm}$ de profundidad). Esta estructura está parcialmente excavada en el nivel C4. El resultado obtenido $(7401 \pm 37 \mathrm{BP}$, 6390-6216 cal BC a 2б) nos hace proponer que el molar datado perteneciera a los estratos mesolíticos y fuera incorporado al sedimento neolítico durante la excavación de la fosa. Por tanto, esta datación no puede ser aceptada. Además, como la datación CNA-2681.1.1, su valor de $\delta 13 \mathrm{C}$ es muy elevado.

\subsection{Un nuevo escenario cronológico}

La revisión y valoración crítica de las dataciones obtenidas en Balma Margineda, así como nuestras nuevas fechas sobre muestras de vida 


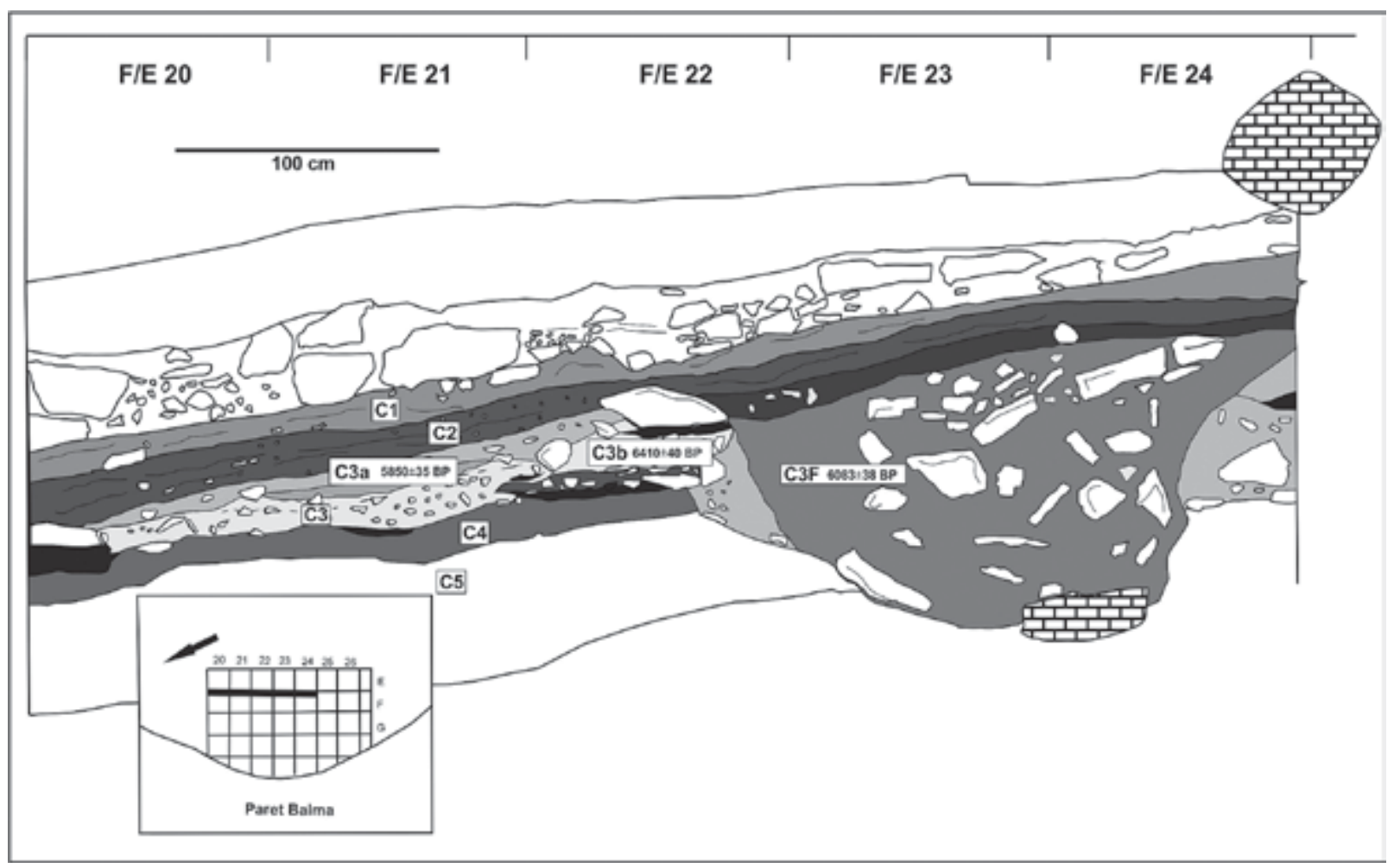

Fig. 4. Sección NE-SO de los cuadros F-E/20-24 de la Balma Margineda. Se indica la localización de las dataciones aceptadas.

corta (fauna doméstica), creemos que cambian sustancialmente la concepción y el marco cronológico que se conocía hasta ahora. La datación de C3b (Beta-325682) resulta mucho más reciente que las ya conocidas para ese nivel y se integra perfectamente en el contexto de las dataciones más antiguas del cardial en el NE peninsular (Morales et al. 2010; Oms et al. 2014). Este nivel se forma después de un importante hiato sedimentario posterior a la ocupación mesolítica (Brochier 1995). Después de otro abandono, también certificado por los estudios geoarqueológicos (Brochier 1995), se abre en el estrato cardial la estructura $\mathrm{C} 3 \mathrm{~F}$, probablemente junto a otras estructuras negativas. Por último, el nivel C3a sella la estructura $\mathrm{C} 3 \mathrm{~F}$ y se extiende en una gran extensión del abrigo, con numerosas estructuras de combustión, agujeros de poste y nuevas fosas.

Las tres ocupaciones datadas de la Balma Margineda, a través de un análisis de $X^{2}$, no fueron próximas en el tiempo. A la vista de la pronta explotación agropastoril de este lugar, podemos deducir que la ocupación fue mucho más continuada. Sin embargo, las matrices sedimentarias ayudaron a que cada ocupación alterara la anterior. Así, la cardial afectó a los niveles mesolíticos, la gran fosa C3F afectó a ambas y el nivel $\mathrm{C} 3 \mathrm{a}$ a los anteriores. Reflejamos las dataciones que, hasta el momento, consideramos plenamente válidas para los inicios del Neolítico de Balma Margineda, en las figuras 4 y 5 y en la tabla 6 .

\section{DISCUSIÓN. LA NUEVA SECUENCIA CRONOLÓGICA Y EL REGISTRO MATERIAL}

El registro cerámico descrito, si se analiza en conjunto, permite detectar ciertos elementos que requieren de una reflexión a tenor de las nuevas dataciones obtenidas. En el nivel C3b, datado en 5472-5322 cal BC, la cerámica cardial es predominante. En esta fase, las grandes concentracio- 


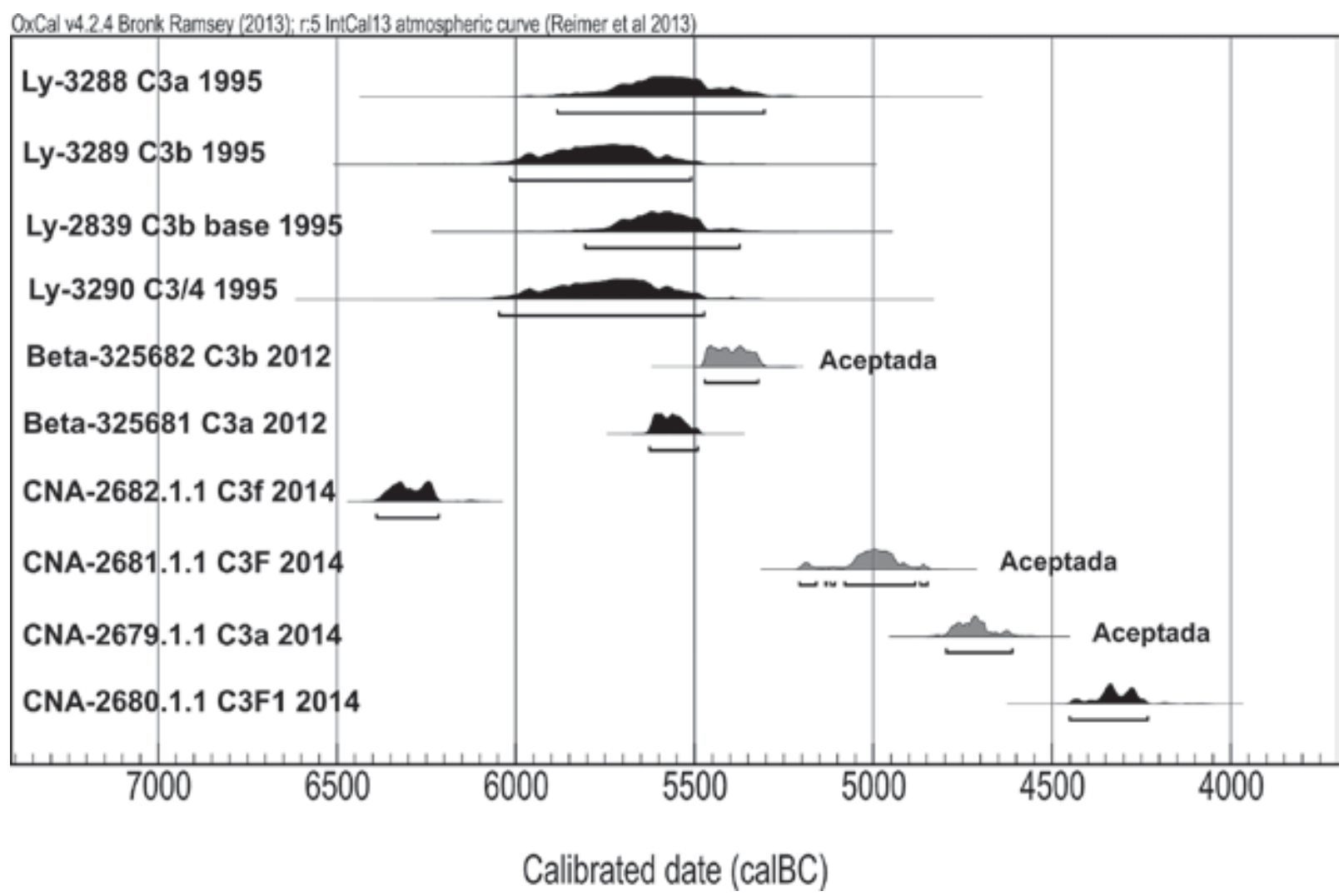

Fig. 5. Representación gráfica de las dataciones calibradas de la Balma Margineda.

\begin{tabular}{|c|c|c|c|c|c|c|c|}
\hline Nivel & Muestra & Método & Lab \# & $\delta^{13} \mathbf{C}$ & BP & Var. & Cal BC 2 $\sigma$ \\
\hline C3b (nivel) & Corylus avellana & AMS & Beta-325682 & -22.8 & 6410 & 40 & $5472-5322$ \\
\hline C3F (fosa) & Ovis/Capra & AMS & CNA-2681.1.1 & -31.3 & 6083 & 38 & $5207-4849$ \\
\hline C3a (nivel) & Ovis/Capra & AMS & CNA-2679.1.1 & -17.15 & 5850 & 35 & $4797-4612$ \\
\hline
\end{tabular}

Tab. 6. Dataciones consideradas válidas de la Balma Margineda calibradas con el programa OxCal v.4.2. con la curva IntCal13 (Reimer et al. 2013).

nes de yacimientos se dan en los territorios del litoral y prelitoral central y meridional (Martín et al. 2010). Fuera de estos ámbitos, los contextos arqueológicos se suelen encontrar aislados. Además de la Balma Margineda, en Catalunya cabe citar los casos de la Balma del Serrat del Pont (Alcalde et al. 2002), en el prepirineo de Girona, y la Cova de la Valldan, en el valle del Segre (Castany et al. 1992). En estos últimos, los conjuntos cerámicos cardiales son muy po- bres: 3 vasos con este tipo de decoración en la Balma del Serrat del Pont y en la Cova de la Valldan, fuera de contexto, sólo 8. Otro ejemplo a comentar es el asentamiento al aire libre de la Font del Ros, en la comarca del Berguedà, zona prepirenaica. Aunque la información publicada sobre la cultura material es escasa, parece ser que la cerámica cardial está más representada (Pallarés et al. 1997). Al norte de los Pirineos, los conjuntos franceses de Grotte de Camprafaud, 


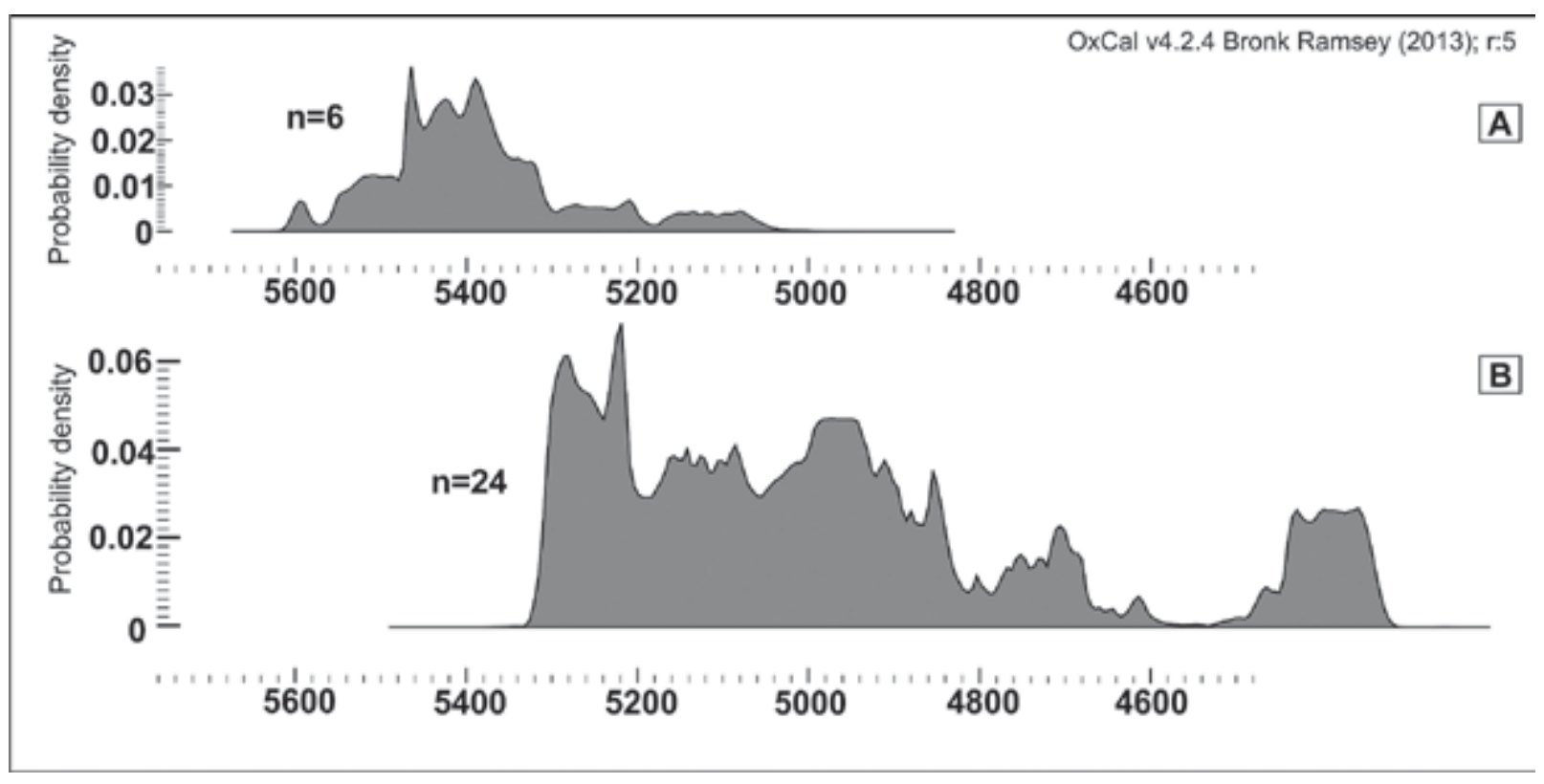

Fig. 6. Representación gráfica de las dataciones calibradas del Neolítico inicial en la región del Pirineo central y oriental: A. conjuntos con cerámicas cardiales; B. conjuntos con cerámicas impresas, cardial y/o boquique esporádico.

Grotte Gazel I y Abri de Jean Cros siguen una dinámica similar ${ }^{2}$ (Guilaine et al. 1979).

La Cueva de Chaves, en el valle del Ebro, es el único yacimiento con un registro cardial muy extenso y bien datado, con fechas que oscilan entre c. 5600-5200 cal BC sobre muestras de vida corta (de taxones domésticos) (Baldellou 2011). En esta fase antigua, también hay restos de cerámicas cardiales en el Abrigo de las Forcas II. En los niveles IV y V de este yacimiento existen 4 fragmentos junto con algunos geométricos de doble bisel (Montes 2014). El problema radica en que en estos niveles no se han documentado restos de especies de animales y vegetales domésticos. Ello, sumado a unas fechas muy elevadas (6750 \pm 40 BP y $6740 \pm 40$ BP: Utrilla y Mazo 2014) hace complicado considerar estos niveles como neolíticos stricto sensu. En general, y a partir de muestras datadas de vida corta, esta fase con cerámicas cardiales tendría una horquilla c. 5500-5100 cal BC (Fig. 6A y Tab. 7).

En la fosa C3F, con una datación de 5207-4849 cal $\mathrm{BC}$, la técnica cardial es residual y son predo-

\footnotetext{
${ }^{2}$ Manen, C. 2000. Le Néolithique ancien entre Rhône et Ebre: analyse des céramiques décorées. Tesis doctoral inédita, L'École des hautes études en sciences sociales. Toulouse, 398 pp.
}

minantes las impresiones simples con la presencia de boquique y recipientes con cordones impresos. Contemporáneos de esta fase, encontramos numerosos yacimientos en la zona Segre-Pirineos, en ocasiones, en contextos geográficos similares al de la Balma Margineda (Oms et al. 2012). Así, los registros de la Cova Colomera (Oms 2008), la Cova Gran de Santa Linya E9 (Polo et al. 2014) y la Cova del Parco (yacimiento recientemente revisado por nosotros ${ }^{3}$ ) tienen claras analogías con esta estructura C3F. Algo más lejanos, otros registros como la Cova dels Trocs, la Cueva del Coro Trasito o la Cueva del Moro de Olvena también presentan esas mismas características (Ramón 2006; Rojo et al. 2013; Clemente et al. 2014). En el sur de Francia, este tipo de registro está bien documentado yacimientos como Grotte Gazel B (Manen 2002), Roc de Dourgne c5 (Guilaine et al. 1993) y Grotte de Camprafaud (Rodriguez 1984) entre otros.

El nivel C3a, con conjuntos cerámicos similares al nivel anterior, cuenta con una datación algo más reciente. Esta fase es especialmente interesante, puesto que se dispone de escasa información

\footnotetext{
${ }^{3}$ Véase n. 1.
} 


\begin{tabular}{|c|c|c|c|c|c|c|}
\hline Yacimiento & Nivel & Muestra & Lab \# & BP & Var. & Cal BC $2 \sigma$ \\
\hline \multicolumn{7}{|c|}{ Niveles con cerámica Cardial } \\
\hline Cueva de Chaves & $\mathrm{Ib}$ & Ovis aries & GrA-38022 & 6580 & 35 & $5614-5478$ \\
\hline Cueva de Chaves & $\mathrm{Ib}$ & Ovis aries & UCI-66317 & 6470 & 25 & $5482-5375$ \\
\hline Cueva de Chaves & $\mathrm{Ib}$ & Bellota & GrA-28341 & 6380 & 40 & $5471-5304$ \\
\hline Cueva de Chaves & Ia & H. humano & GrA-26912 & 6230 & 45 & $5308-5057$ \\
\hline Balma Serrat del Pont & III.4 & Sus scropha & Beta-172521 & 6470 & 40 & $5509-5344$ \\
\hline Balma Margineda & $\mathrm{C} 3 \mathrm{~b}$ & Corylus a. & Beta-325682 & 6410 & 40 & $5472-5322$ \\
\hline \multicolumn{7}{|c|}{ Niveles con cerámica impresa ( $y$ boquique y/o cardial en baja cantidad) } \\
\hline Cova Colomera & CV10 & Buxus s. & Beta-279478 & 6180 & 40 & $5286-5002$ \\
\hline Cova Colomera & CE13-14 & Triticcum a/d & Beta-240551 & 6150 & 40 & $5216-4993$ \\
\hline Cova Colomera & CE12 & Buxus s. & Beta-248523 & 6020 & 40 & $5011-4799$ \\
\hline Cova Colomera & CE14 & Triticcum a/d & OxA-23634 & 6170 & 30 & $5216-5031$ \\
\hline Balma Margineda & $\mathrm{C} 3 \mathrm{~F}$ & Ovis/Capra & CNA-2681.1.1 & 6083 & 38 & $5207-4849$ \\
\hline Balma Margineda & $\mathrm{C} 3 \mathrm{a}$ & Ovis/Capra & CNA-2679.1.1 & 5850 & 35 & $4797-4612$ \\
\hline Cova Gran & E9 & Bellota & Beta-265982 & 6020 & 50 & $5045-4791$ \\
\hline Cova dels Trocs & Trocs I UE105 & H. humano & Mams-16163 & 6285 & 25 & $5312-5219$ \\
\hline Cova dels Trocs & Trocs I UE63 & H. humano & Mams-16159 & 6280 & 25 & $5311-5218$ \\
\hline Cova dels Trocs & Trocs I UE101 & H. humano & Mams-16164 & 6249 & 25 & $5310-5080$ \\
\hline Cova dels Trocs & Trocs I UE20 & H. humano & Mams-16168 & 6249 & 28 & $5310-5078$ \\
\hline Cova dels Trocs & Trocs I UE20 & H. humano & Mams-16166 & 6234 & 28 & $5303-5075$ \\
\hline Cova dels Trocs & Trocs I UE85 & H. humano & Mams-16162 & 6218 & 24 & 5294-5068 \\
\hline Cova dels Trocs & Trocs I UE82 & H. humano & Mams-16161 & 6217 & 25 & 5294-5066 \\
\hline Cova dels Trocs & Trocs I UE53 & Semilla & Beta-316512 & 6080 & 40 & $5206-4847$ \\
\hline Cova dels Trocs & Trocs I UE20 & Semilla & Beta-284150 & 6070 & 40 & $5202-4844$ \\
\hline Cova dels Trocs & Trocs I UE63 & Fauna & Beta-295782 & 6060 & 40 & $5195-4842$ \\
\hline Cova dels Trocs & Trocs I UE16 & Semilla & Beta-316514 & 6050 & 40 & $5056-4836$ \\
\hline Cueva Coro Trasito & UE2013 & Bos taurus & Beta-366546 & 6150 & 40 & $5216-4993$ \\
\hline Cueva Coro Trasito & UE3002 & Corylus a. & CNA-2520 & 5850 & 35 & $4797-4612$ \\
\hline Cueva Coro Trasito & UE3006 & Buxus sp. & Beta-358571 & 5990 & 40 & $4992-4786$ \\
\hline Cova dels Trocs & Trocs II UE14 & Semilla & Beta-316511 & 5590 & 40 & $4494-4350$ \\
\hline Cova dels Trocs & Trocs II UE8 & Semilla & Beta-316515 & 5590 & 40 & $4494-4350$ \\
\hline Cova dels Trocs & Trocs II UE77 & Semilla & Beta-319513 & 5580 & 40 & $4488-4347$ \\
\hline
\end{tabular}

Tab. 7. Dataciones consideradas válidas del Neolítico inicial en la región del Pirineo central y oriental (Alcalde et al. 2002; Baldellou 2011; Oms et al. 2013; Rojo et al. 2013; Polo et al. 2014; Clemente et al. 2015; Martins et al. 2015), calibradas mediante el software OxCal v.4.2. con la curva IntCal13 (Reimer et al. 2013). H. Hueso; Corylus a. Corylus avellana.

cultural de otros yacimientos de la región durante la primera mitad del V milenio cal BC. En general, tanto en Catalunya como el sur de Francia, a partir del cambio de milenio, las decoraciones impresas disminuyen en importancia a favor de las inciso-impresas y sobre todo las plásticas), 
dentro de los cánones epicardiales clásicos (Manen 2002; Martín et al. 2010). Sin embargo, y tal como se observa en Balma Margineda C3a (y también en Trocs, fase II), la continuidad en los tipos de decoración es muy evidente, incluso con la presencia -testimonial- de cerámica con decoración cardial. En este sentido, los materiales de C3a y de C3F se asemejan más a las colecciones del valle del Ebro y del interior del Languedoc, que no al típico epicardial de las zonas litorales y prelitorales del Mediterráneo. En la misma Andorra, durante la segunda mitad del V milenio cal $\mathrm{BC}$, las decoraciones impresas son muy escasas a favor de decoraciones plásticas ortogonales y/o arqueadas (Martínez et al. 2012), algo que no sucede en Trocs fase II, con la pervivencia de las impresiones hasta c. 4500-4400 cal BC (Rojo et al. 2013). Por lo tanto, esta fase de cerámicas impresas, con presencia de cardial y/o boquique tendría su máxima representación entre c.5300-4700 cal BC (Fig. 6 y Tab. 7), alargándose puntualmente en algunos ámbitos hasta c.4300 cal BC.

Desde el punto de vista de la industria lítica, el único elemento que nos puede ofrecer algunas pautas a nivel crono-cultural son los microlitos geométricos. Del conjunto analizado (18 geométricos), cuatro se pueden asimilar a las puntas de 'Jean Cros', objetos que se sitúan en una franja cronológica amplia, entre el 5200 y el 4400 cal BC (Guilaine 1979). Se trata de microlitos alargados, simétricos, de forma triangular, modelados por un retoque inverso, abrupto o semi-abrupto y, en la cara opuesta, un sucesivo retoque directo, cubriente o semi-cubriente. Junto con las puntas de 'Montclus', del que las 'flechas de Jean-Cros' representan una variante con lados rectilíneos o convexos (Guilaine 1979; Oms et al. 2012), son proyectiles característicos del neolítico del sur y sur-oeste de Francia (Binder 1987). Son habituales en yacimientos como Roc de Dourgne y Grotte Gazel (Guilaine 1979).

Sin entrar en el origen de dichas tipologías, es destacable que son morfologías más bien raras en el panorama del cardial y epicardial del litoral catalán o del valle del Ebro, donde las formas más características se relacionan con los llamados "segmentos de doble bisel", caracterizados por un retoque plano bifacial, más o menos invasivo (Alday et al. 2012; Gibaja y Clop 2012). De todas formas, algunos elementos triangulares con estilo y forma parecidos a las flechas "Jean Cros" han sido reconocidos en las industrias de Cova de les Cendres (García-Puchol 2009) y Cueva de Cocina (Fortea 1973). Sin embargo, podríamos catalogar su presencia como esporádica. Además de los elementos de tipo "Jean Cros", en la Balma Margineda encontramos también puntualmente elementos triangulares con doble bisel de forma alargada. Morfologías, en este caso, más cercanas a algunos microlitos que se conocen en contextos aragoneses como los hallados en el nivel V del abrigo de Forcas II (Utrilla y Mazo 2014) y en el nivel cardial de la Cueva de Chaves (Ib) (Cava 2000). En todo caso, la Balma Margineda se caracteriza por la notable variabilidad de formas de los microlitos geométricos, sean segmentos, trapecios o triángulos. a

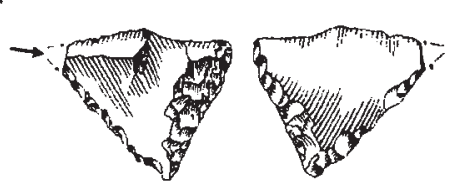

d

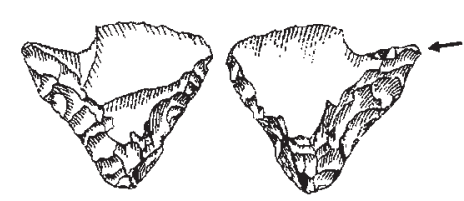

b
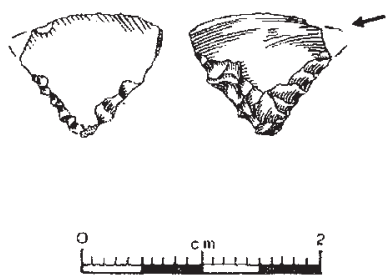

e

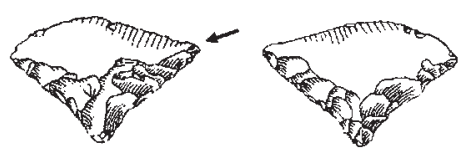

c
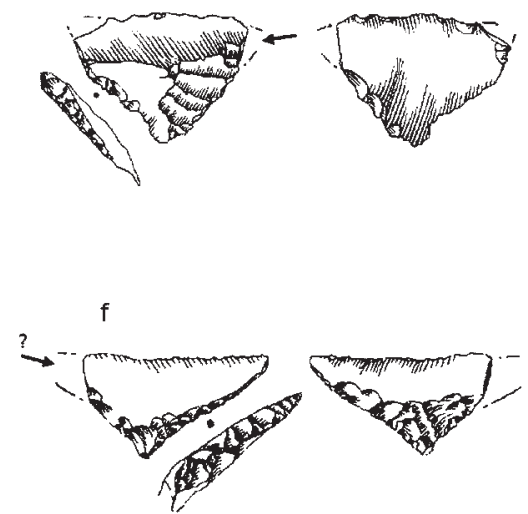

Fig. 7. Microlitos geométricos de Balma Margineda con evidencias de fracturas de impacto: a-c triángulos de tipo Jean-Cros sensu lato; d-e triángulos de doble bisel; f triángulo de tipo Cocina.

Trab. Prehist., 73, N. ${ }^{\circ}$ 1, enero-junio 2016, pp. 29-46, ISSN: 0082-5638

doi: $10.3989 /$ tp.2016.12162 
En la Balma Margineda, tanto los elementos más similares a las flechas "Jean Cros" (Fig. 7ac), como los triángulos de doble bisel (Fig. 7de), aparecen distribuidos de forma uniforme entre las diferentes unidades estratigráficas (C.3a, C.3b, C.3b base y C.3f y C.3F). En definitiva, los microlitos geométricos de la Balma Margineda indican la existencia de tradiciones y esquemas técnicos compartidos con otros contextos arqueológicos de toda el área pirenaica y zonas adyacentes. En todo caso, los diversos tipos y variantes no son exclusivos de ninguna región.

\section{CONCLUSIONES}

Desde el año 1995 hasta la actualidad, en la Balma Margineda se han realizado 10 dataciones radiocarbónicas con el fin de caracterizar cronológicamente las primeras ocupaciones neolíticas. Sin embargo, tanto por el método empleado en el pasado (datación convencional), como por las dificultades tafonómicas advertidas en el yacimiento, solamente tres fechas podemos considerarlas válidas en relación a este periodo. Por ese motivo es de vital importancia detectar los problemas de conservación del registro arqueológico, elegir muestras de vida corta, preferiblemente domésticas (C3F y $\mathrm{C} 3 \mathrm{a})$ o recolectadas, y procedentes de una torrefacción en una estructura de combustión (C3b).

Las dataciones realizadas por nosotros en el último año han rejuvenecido la cronología en una media de 500 años para cada nivel. Ello invalida la correlación de la Balma Margineda con cualquier tipo de continuidad de poblamiento entre el Mesolítico y el Neolítico antiguo y otras propuestas basadas en su excesiva antigüedad inicial. Al mismo tiempo, demuestran que la Balma Margineda se correlaciona con otros asentamientos aislados del Neolítico cardial pleno y cardial final-epicardial antiguo de la segunda mitad del VI milenio cal BC y proporciona los primeros datos de la región sobre su ocupación alrededor del $\mathrm{V}$ milenio cal BC.

Además, a pesar del rejuvenecimiento de su cronología, la Balma Margineda sigue representando uno de los asentamientos más antiguos del Neolítico antiguo cardial en la cordillera pirenaica. Posteriormente, este mismo yacimiento continuará ocupándose con grupos cuya cerámica está caracterizada por la decoración impresa y bo- quique. Paralelos podemos encontrarlos en las ya mencionadas Cova de Els Trocs (Rojo et al. 2013) y Cova Colomera (Oms et al. 2013), así como en el abrigo de Coro Trasito (Clemente et al. 2014) y la Espluga de la Puyascada (Mazzucco et al. 2013), ambos situados en valles secundarios de la cuenca del Río Cinca. Todas estas ocupaciones presentan unos niveles con cronologías comprendidas aproximadamente entre c. 5200-4600 cal $\mathrm{BC}^{4}$.

Se trata de yacimientos que nos hablan de ocupaciones de carácter estacional, cuyos depósitos sedimentarios se han formado como resultado de breves y reiteradas frecuentaciones. Su funcionalidad, en todo caso, parece vincularse a prácticas pastoriles, con ciertas diferencias en función de las actividades del ciclo ganadero llevadas a cabo (reproducción, cría, engorde y faenas del ganado). Al margen de dichas prácticas, se registran otras actividades, vinculadas por ejemplo al almacenamiento, al consumo de productos animales y vegetales o a la caza, que, a pesar de representar una actividad secundaria y no especializada, se documenta a partir del registro lítico y/o faunístico.

En definitiva, el nuevo cuadro cronológico propuesto por la Balma Margineda, parece encajar de forma más coherente con las dinámicas humanas y culturales actualmente documentadas en el Pirineo Central y Oriental. El yacimiento atestigua una ocupación que se relaciona con probables prácticas de estabulación, de matanza y consumo del ganado, especialmente caprino, en un momento en el cual se evidencia una incipiente presión antrópica sobre las zonas de media y alta montaña en toda la cordillera. Tanto a nivel artefactual como a nivel económico, el yacimiento muestra una coherencia con los contextos de la región, puesto que comparten tradiciones técnicas y decorativas, tanto para aquellos situados al sur como al norte de los Pirineos.

\section{AGRADECIMIENTOS}

Patricia Martín eligió y determinó las muestras zooarqueológicas usadas para datar el yacimiento. Las fechas radiocarbónicas del Centro Nacional

\footnotetext{
${ }^{4}$ Véase n. 1.
} 
de Aceleradores presentadas aquí se han llevado a cabo en el marco del proyecto "Aproximación a las primeras comunidades neolíticas del NE peninsular a través de sus prácticas funerarias" (HAR2011-23149). Agradecemos al Departament de Patrimoni Cultural de Andorra (Àmbit de Recerca Històrica) el permiso para realizar las dataciones y las facilidades para poder analizar el material cerámico y lítico. Las correcciones propuestas por los revisores anónimos han mejorado enormemente la calidad de este trabajo.

\section{BIBLIOGRAFÍA}

Alcalde, G.; Molist, M. y Saña, M. 2002: Procés d'ocupació de la bauma del Serrat del Pont la Garrotxa) entre 5480 i 2900 cal AC. Publicacions Eventuals d'Arqueologia de la Garrotxa 7, Museu Comarcal de la Garrotxa. Olot.

Alday, A.; Montes, L. y Baldellou, V. 2012: "El Neolítico en la Cuenca del Ebro". En M. Rojo, R. Garrido y I. García (eds.): El Neolítico en la Península Ibérica y su contexto europeo. Ed. Cátedra. Madrid: 291-331.

Antolín, F. 2008: Aproximació a l'estudi de la percepció i la interacció amb l'entorn vegetal en societats caçadores recol-lectores $i$ agricultores ramaderes (10,000-4000 cal ANE). Resultats de l'estudi arqueobotànic del jaciment arqueològic de la Cova de Can Sadurní (Begues, Baix Llobregat). Tesis de màster, Universitat Autònoma de Barcelona. http:// hdl.handle.net/2072/40656 (consulta 1-III-2015).

Baldellou, V. 2011: "La cueva de Chaves (BastarásCasbas, Huesca)". En J. Bernabéu, M. A. Rojo y L1. Molina (ed.): Las primeras producciones cerámicas: el VI milenio cal AC en la Península Ibérica. Saguntum PLAV Extra-12, Universitat de València: 141-144.

Baldellou, V. y Utrilla P. 1999: "Le Néolithique en Aragon". En J. Vaquer (ed.): Le Néolithique $d u$ Nord-Ouest méditerranéen. Actes du XXIVe Congrès préhistorique de France (Carcassonne 1994): 225-237. Paris.

Beeching, A. y Brochier, J. L. 2003: "Espace et temps à la prehistoire: biaisage et problèmes de representation". En J. Gascó, X. Gutherz y P. A. de Labriffe (eds.): Temps et espaces culturels du 6e au $2 e$ millénaire en France du Sud. Actes des quatrièmes Rencontres Méridionales de Préhistoire Récente (Nimes 2000). Monographies d'Archéologie Méditerranéenne 15. Lattes: 21-32.

Bernabéu, J. 2006: "Una visión actual sobre el origen y difusión del Neolítico en la Península Ibérica c. 5600-5000 cal BC". En O. García-Puchol y J. E.
Aura (ed.): El Abric de la Falguera (Alcoi, Alacant). 8000 años de ocupación humana en la cabecera del río Alcoi, Ajuntament d'Alcoi, Dipt d'Alacant. Museo Arqueológico de Alicante - MARQ. Alicante: $189-211$.

Bernabéu, J.; Barton, C. y Pérez-Ripoll, M. 2001: “A taphonomic perspective on Neolithic beginnings: theory, interpretation and empirical data in the western Mediterranean". Journal of Archaeological Science 28-6: 597-612.

Binder, D. 1987 : Le Néolithique Ancien Provençal: Typologie et technologie desoutillages lithiques. XXIV supplement à Gallia Prehistoire, Editions du CNRS. Paris.

Bosch, À.; Buxó, R.; Palomo, A.; Buch, M.; Mateu, J.; Tabernero, E. y Casadevall, J. 1998: El poblat neolític de Plansallosa. L'explotació del territorio dels primers agricultors-ramaders de l'Alta Garrotxa. Publicacions Eventuals d'Arqueologia de la Garrotxa 5, Museu Comarcal de la Garrotxa. Olot.

Brochier, J.-E. 1995: "Estudi geoarqueològic dels dipòsits holocens de la Balma de la Margineda: capes 1 a 6". En J. Guilaine y M. Martzluff (eds.): Les excavacions a la balma de la Margineda (19791991) 1, Sèrie Prehistòria d'Andorra, Ed. Govern d'Andorra. Andorra: 56-89.

Bronk Ramsey, C. 2013: OxCal 4.2.2 Manual. https:// c14.arch.ox.ac.uk

Castany, J.; Ramon, M. y Guerrero, L. 1992: "La Bòfia de la Valldan (Odèn-Solsonès) i el Neolític Antic del Pre-Pirineu de Lleida". Ilerda, Humanitats 50: 61-94.

Cava, A. 2000: "La industria lítica del Neolítico de Chaves (Huesca)". Saldvie, Estudios de prehistoria y arqueologia 1: 75-162.

Clemente, I.; Gassiot, E.; Rey, J.; Mazzucco, N. y Obea, L. 2014: “'Cort o Transito' -Coro Trasito- O Corral de Tránsito: una cueva pastoral del Neolítico antiguo en el corazón de Sobrarbe". En I. Clemente, E. Gassiot y J. Rey (eds.): Sobrarbe antes de Sobrarbe: pinceladas de historia de los Pirineos. Centro de Estudios de Sobrarbe e Instituto de Estudios Altoaragoneses. Cometa S.A. Zaragoza: 11-32.

Fortea, J. 1973. Los complejos microlaminares $y$ geométricos del Epipaleolítico Mediterráneo español. Universidad de Salamanca. Salamanca.

García-Puchol, O. G. 2009: "La piedra tallada del neolítico en Cendres". En J. Bernabeu y Ll. Molina (eds.): La Cueva de les Cendres. M.A.R.Q., Serie Mayor 6, Diputación Provincial de Alicante. Alicante: 85-104.

Gibaja, J. F. y Clop, X. 2012: "El Neolítico en Cataluña". En M. Rojo, R. Garrido y I. García (eds.): El Neolítico en la Península Ibérica y su contexto europeo. Ed. Cátedra. Madrid: 333 -370.

Guilaine, J. 1979: "La 'flèche de Jean-Cros' dans son contexte méridional". En J. Guilaine, J. Gascó, J. Vaquer y M. Barbaza (eds.): L'abri Jean Cros. Essai

Trab. Prehist., 73, N. ${ }^{\circ}$ 1, enero-junio 2016, pp. 29-46, ISSN: 0082-5638

doi: $10.3989 /$ tp.2016.12162 
sur un groupe humain du Néolithique ancien dans son environnement. L'École des hautes études en sciences sociales, Centre d'anthropologie des sociétés rurales. Toulouse: 117-126.

Guilaine, J. 1993: "Questions ouvertes sur la néolithisation de la haute vallée de l'Aude". En J. Guilaine, M. Barbaza, J. Gascó, D. Geddès, J. Coularou, J. Vaquer, J.-E. Brochier, F. Briois, J. André, G. Jalut y J.-L. Vernet (eds.): Dourgne, derniers chasseurscollecteurs et premiers éleveurs de la haute vallée de l'Aude. L'Ecole des hautes études en sciences sociales, Centre d'anthropologie des sociétés rurales. Toulouse: 443-476.

Guilaine, J.; Barbaza, M. y Martzluff, M. (ed.) 2008: Les excavacions a la Balma Margineda (19791991). Sèrie Prehistòria d'Andorra IV. Andorra.

Guilaine J.; Gascó J.; Vaquer, J. y Barbaza M. 1979: L'abri Jean Cros. Essai sur un groupe humain du Néolithique ancien dans son environnement. L'École des hautes études en sciences sociales, Centre d'anthropologie des sociétés rurales. Toulouse.

Guilaine, J.; Barbaza M.; Gascó, J.; Geddes, D.; Coularou, J; Vaquer, J.; Brochier, J.-E.; Briois, F.; André, J.; Jalut G. y Vernet, J.-L. 1993: Dourgne, derniers chasseurs-collecteurs et premiers éleveurs de la haute vallée de l'Aude. L'École des hautes études en sciences sociales, Centre d'anthropologie des sociétés rurales. Toulouse.

Guilaine, J. y Martzluff, M. 1995a: Les excavacions a la balma de la Margineda (1979-1991). Serie Prehistòria d'Andorra, Ed. Govern d'Andorra. Andorra.

Guilaine, J. y Martzluff, M. 1995b: "Estratigrafia general del jaciment". En J. Guilaine y M. Martzluff (dir.) Les excavacions a la balma de la Margineda (1979-1991). 1 Sèrie Prehistòria d'Andorra. Ed. Govern d'Andorra. Andorra: 34-54.

Guilaine, J. y Martzluff, M. 1995c: "La cultura material de les ocupacions neolítiques (conjunts de la capa 3, excavacions 1979-1991)". En J. Guilaine y M. Martzluff (eds.): Les excavacions a la balma de la Margineda (1979-1991) I. Edicions del Govern d'Andorra. Andorra: 133-269.

Guilaine, J.; Abelanet, J.; Coularou, J.; Martzluff, M.; Pons, P. y Rivenq, C. 1995a: "Estudi espacial de les fases del conjunt neolític de la capa 3". En J. Guilaine y M. Martzluff (ed.): Les excavacions a la balma de la Margineda (1979-1991) 1, Serie Prehistòria d'Andorra, Ed. Govern d'Andorra. Andorra: 116-131.

Guilaine, J.; Evin, J. y Martzluff, M. 1995b: "Datacions isotòpiques de les capes 1 a 6 de la Balma de la Margineda". En J. Guilaine y M. Martzluff (eds.): Les excavacions a la balma de la Margineda (19791991) 1, Serie Prehistòria d'Andorra, Ed. Govern d'Andorra. Andorra: 91-95.

Guilaine, J.; Llongueras, Ll.; Marcet, R.; Petit, M. A. y Vaquer, J. 1981: "La cova del Toll (Moià), Barcelona”. En El neolític a Catalunya. Taula Ro- dona de Montserrat (Montserrat 1980): 113-122. Montserrat.

Heinz, C. y Vernet, J.-L. 1995: “Anàlisi antracològica dels nivells mesolítics i del neolític antic de la Balma de la Margineda. Paleoecologia i relacions home-vegetació". En J. Guilaine y M. Martzluff (eds.): Les excavacions a la balma de la Margineda (1979-1991) 3. Serie Prehistòria d'Andorra. Ed. Govern d'Andorra. Andorra: 26-64.

Isern, N.; Fort, J. y Vander Linden, M. 2012: "Space competition and time delays in human range expansions. Application to the Neolithic transition". Plos One 7.12: 1-9. doi:10.1371/journal.pone.0051106

Maluquer de Motes, J. 1962: "Prehistoria de Andorra". Zephyrus XIII: 5-15.

Manen, C. 2002: "Structure et identité des styles céramiques du Néolithique ancien entre Rhône et Èbre". Gallia Préhistoire 44: 121-166.

Manen, C. y Guilaine, J. 2010: “Aspects géographiques et chronoculturels du Néolithique ancien languedocien". En C. Manen, F. Convertini, D. Binder y I. Sénépart (eds.): Premières societés paysannes de Méditerrannée occidental. Structures des productions céramiques. Mémoire 51 Société Préhistorique Française. Toulouse: 179-190.

Marinval, P. 1995: "Recol-lecció i agricultura de 1>epipaleolític al neolític antic: anàlisi carpològica de la Balma Margineda". En J. Guilaine y M. Martzluff (eds.): Les excavacions a la balma de la Margineda (1979-1991) 3, Serie Prehistòria d'Andorra, Ed. Govern d'Andorra. Andorra: 65-77.

Martín, A. 1993: "Reflexión sobre el estado de la investigación del Neolítico en Cataluña y su reflejo en la cronología radiométrica". Empúries 48-50, II: 84-103.

Martín, A.; Edo, M.; Tarrús, J. y Clop, X. 2010. “Le Néolithique ancien de Catalogne (VI - première moitié du V millénaire av. J.C.). Les séquences Chronoculturels". En C. Manen, F. Convertini, D. Binder y I. Sénépart (ed.): Premières societés paysannes de Méditerrannée occidental. Structures des productions céramiques. Mémoire 51 Société Préhistorique Française. Toulouse 2007: 197-214.

Martins, H.; Oms, F. X.; Pereira, L; Pike, A. y Zilhão, J. 2015: "Radiocarbon dating the beginning of the Neolithic in Iberia: new results, new problems". Journal of Mediterranean Archaeology 28.1: 105131.

Martínez, P.; Vaquer, J.; Vidal, À.; Fortó, A. y Maese, X. 2012: "Primers apunts sobre els materials del jaciment neolític de Juberri (Andorra)". IV Col-loqui d'Arqueologia d'Odèn (Odèn-Cambrils 2011): 4756. Odèn.

Mazzucco, N.; Clemente, I.; Baldellou, V. y Gassiot, E. 2013: "The management of lithic resources during the $\mathrm{V}$ millennium cal BC at Espluga de la Puyascada (La Fueva, Huesca)". Preistoria Alpina 47: 57-67. 
Montes, L. 2014: “Las cerámicas neolíticas del sector oeste de Forcas II'. En P. Utrilla y C. Mazo (ed.): La Peña de las Forcas (Graus, Huesca). Un asentamiento estratégico en la confluencia del Ésera y el Isábena. Monografías Arqueológicas. Prehistoria 46, Universidad de Zaragoza. Zaragoza: 243-264.

Morales, J. I.; Fontanals, M.; Oms, F. X. y Vergès J. M. 2010: "La chronologie du Néolithique ancien cardial du Nord-Est de la péninsule Ibérique. Datations, problématique et méthodologie". L'Anthropologie 114: 427-444.

Oms, F. X. 2008: “Caracterització tècnica, tipològica i cronològica de les ceràmiques del Neolític antic de la Cova Colomera (Prepirineu de Lleida)". Archivo de Prehistoria Levantina 27: 51-80.

Oms, F. X.; Esteve, X.; Mestres, J.; Martín, P. y Martins, H. 2014: "La neolitización del nordeste de la Península Ibérica: datos radiocarbónicos y culturales de los asentamientos al aire libre del Penedès". Trabajos de Prehistoria 71 (1): 43-56.

Oms, F. X.; López-García, J. M.; Mangado, X.; Martín, P.; Mendiela, S.; Morales, J. I.; Rodríguez, A.; Rodríguez-Cintas, A. y Yubero, M. 2013: "Hàbitat en cova i espai pels ramats ca. 6200-6000 BP: dades preliminars de la Cova Colomera (Prepirineu de Lleida) durant el neolític antic". Saguntum PLAV 45: 25-38.

Oms, F. X.; Petit, M. A.; Morales, J. I. y García, M. S. 2012: "Le processus de néolithisation dans les Pyrénées orientales. Occupation du milieu, culture matérielle et chronologie". Bulletin de la Société Préhistorique Française 109, 4: 651-670.

Pallarés, M.; Bordas, A. y Mora, R. 1997: "El proceso de neolitización en los Pirineos Orientales. Un modelo de continuidad entre los cazadores-recolectores neolíticos y los primeros grupos agropastoriles". Trabajos de Prehistoria 54 (1): 121-141.

Petit, M. 2001: "Els primers pagesos i ramaders". En J. Giralt y T. Carreras Rossell (ed.): La Noguera Antiga. Des dels primers pobladors fins als visigots. Museu d'Arqueologia Catalunya y Museu de Balaguer. Barcelona: 46-62.

Polo, A.; Martínez-Moreno, J.; Benito-Calvo, A. y Mora, R. 2014: "Prehistoric herding facilities: site formation and archaeological dynamics in Cova
Gran de Santa Linya (Southeastern Prepyrenees, Iberia)". Journal of Archaeological Science 41: 784-800.

Ramón, N. 2006. "La cerámica del Neolítico Antiguo en Aragón". Caesaragusta 77: 9-353.

Reimer, P. J. ; Bard, E. ; Bayliss, A. ; Beck, J. W. ; Blackwell, P. G.; Bronk Ramsey, C.; Buck, C.E.; Cheng, H.; Edwards, R. L.; Friedrich, M.; Grootes, P. M.; Guilderson, T. P.; Haflidason, H.; Hajdas, I.; Hatté, C.; Heaton, T. J.; Hoffmann, D. L.; Hogg, A. G.; Hughen, K. A.; Kaiser, K. F.; Kromer, B.; Manning, S. W.; Niu, M.; Reimer, R. W.; Richards, D. A.; Scott, E. M.; Southon, J. R.; Staff, R. A.; Turney, C. S. M. y van der Plicht, J. 2013: "IntCal13 and Marine 13 radiocarbon age 22 calibration curves 0-50,000 years cal BP". Radiocarbon 55 (4): 1869-1887.

Rodriguez, G. 1984 : La grotte de Camprafaud: contribution à l'étude du Néolithique en Languedoc central. Office de la culture du Languedoc-Roussillon. Montpellier.

Rojo, M.; Peña-Chocarro, L.; Royo, I.; Tejedor, C.; Martínez de Lagrán, I.; Arcusa, H.; Garrido-Pena, R.; Moreno, M.; Mazzucco, N.; Gibaja, J.F.; Ortega, D.; Kromer, B. y Alt, K. 2013: "Pastores trashumantes del Neolítico Antiguo en un entorno de alta montaña: secuencia crono-cultural de la Cova de Els Trocs, San Feliú de Veri (Huesca)". Boletin del Seminario de Arte y Arqueología. Arqueología 13: 9-54.

Utrilla, P. y Mazo, C. 2014: La Peña de las Forcas (Graus, Huesca). Un asentamiento estratégico en la confluencia del Ésera y el Isábena. Monografías Arqueológicas, Prehistoria 46, Universidad de Zaragoza. Zaragoza.

Valdeyron, N.; Manen, C. y Bosc-Zanardo, B. 2013: "Mésolithique récent/final et néolithisation du SudOuest de la France: vers de nouvelles perspectives?". En J. Jaubert, N. Fourment y P. Depaepe (ed.): Transitions, ruptures et continuité en Préhistoire, actes du XVIIe Congrès préhistorique de France (Bordeaux 2010): 373-390. Paris.

Zilhão, J. 2011: “Time is on my side...". En A. Hadjikoumis, E. Robinson y S. Viner (eds.): The dynamics of Neolithisation in Europe. Studies in honour of Andrew Sherrat. Oxbow books. Oxford: 46-65.

Trab. Prehist., 73, N. ${ }^{\circ}$ 1, enero-junio 2016, pp. 29-46, ISSN: 0082-5638

doi: $10.3989 /$ tp.2016.12162 